\title{
The benign online disinhibition effect: Could situational factors induce self-disclosure and prosocial behaviors?
}

\author{
Noam Lapidot-Lefler ${ }^{1}$, Azy Barak ${ }^{2}$ \\ ${ }^{1}$ The Max Stern Yezreel Valley College \& Oranim College for Education, Israel \\ ${ }^{2}$ University of Haifa, Israel
}

\begin{abstract}
The current study, which focuses on the benign effects of disinhibition, was designed as a continuation of an earlier study conducted on the toxic effects of online disinhibition (LapidotLefler \& Barak, 2012). Using a factorial design, the study examined the effects of three online situational factors-anonymity, invisibility, and lack of eye contact-on inducing self-disclosure and prosocial behaviors as expressions of benign online disinhibition. Random pairs of adult strangers $(n=144)$ discussed a dilemma and were required to reach a joint solution using online chat. Self-disclosure and prosocial behavior effects were measured using participants' self-reports, expert judges' ratings of chat transcripts, and textual analyses of the conversations. Results suggested that the interaction between anonymity and invisibility had a significant effect on the revealing of emotions. Lack of eye contact, the interaction between anonymity and invisibility and the interaction between lack of eye contact and invisibility had a significant effect on the inducement of first-person words. The interaction between anonymity, invisibility and lack of eye contact had significant effects on the total self-disclosure score, yet no significant effects were found for prosocial behaviors. A discussion of the findings with regard to previous research on toxic online disinhibition suggests that different factors play a role in the inducement of benign vs. toxic online disinhibition effects. More research is required to substantiate current findings and determine the nature of the contribution of each situational factor.
\end{abstract}

Keywords: online communication, benign disinhibition, anonymity, invisibility, eye contact

\section{Introduction}

\section{Online Disinhibition and the Positive (Benign) Online Disinhibition Effect}

The online disinhibition effect is a term used to describe the lowering of psychological restraints, which often serve to regulate behaviors in the online social environment (Joinson, 2007; Suler, 2004). It is reflected in reduced behavioral inhibitions, a lowered regard for behavioral boundaries while in cyberspace, and can be expressed in various online interpersonal behaviors which can be positive or negative. Suler $(2004,2005)$ refers to the positive manifestations as benign disinhibition. These can include efforts to improve self-understanding and personal development, assistance in resolving interpersonal and intrapersonal conflicts, or exploration of new emotional or experiential realms of one's identity. These are equivalent to the notion of working through an experience, as described in psychodynamic theory, or self-actualization, to use the humanistic term (Suler, 2004). The positive (or the benign) online disinhibition effect can also have social ramifications such as philanthropic gestures, giving advice and emotional support and greater self-disclosure. 
Benign online disinhibition: Online self-disclosure. A prominent example of personal ramifications of benign online disinhibition is self-disclosure, defined as revealing personal information to others. Selfdisclosure has been the focus of numerous studies, some of which observed its emergence in the context of interpersonal interactions in general (Archer, 1980; Derlega, Metts, Petronio, \& Margulis, 1993), while more recent publications related to it specifically in the context of computer-mediated communications (CMC) (Gibbs, Ellison, \& Lai, 2011; Joinson, Paine, \& Buchanan, 2008). Researcher report greater online self-disclosure (Joinson \& Paine, 2007; Sillence \& Briggs, 2007). This disclosure can be negative or positive. Self-disclosure in the online environment could be considered toxic disinhibition if it is involves flaming or embarrassing content (Ben-Ze'ev, 2004; Suler, 2004). On the other hand, Yang, Yang, \& Chiou (2010), found that adolescents were willing to divulge personal information online despite the vastness of the public forum, and felt comfortable doing so. Also, Bareket-Bojmel and Shahar (2011) found that students would reveal previously untold secrets or personally embarrassing details, in an online chat. Participants in online chats even feel relieved when sharing their secrets (Magsamen-Conrad, BillotteVerhoff, \& Greene, 2014).

Given that the online environment is characterized by fewer inhibitions and behavioral boundaries, selfdisclosure occurs sooner and is often more intimate than it would be in similar, first-time face-to-face (FtF) encounters (e.g., Davis, 2012). The anonymity of cyberspace provides an optimal opportunity for communicators to share intimate and sensitive issues, in a typical pattern that is intensified by reciprocity (Barak \& Gluck-Ofri, 2007; Jiang, Bazarova, \& Hancock, 2013). In fact, it has been claimed that interpersonal relationships established online are no less significant and intimate than FtF relationships (e.g., Anolli, Villani, \& Riva, 2005; Manago, Taylor, \& Greenfield, 2012). Enhanced by multimedia and hyperlinks that help convey a personal message, Barak (2007) argued that online relationships can help strengthen-or even be stronger than-offline relationships (Reich, Subrahmanyam, \& Espinoza, 2012; Walther, 2007). This quality can be achieved due to the characteristics of the Internet and the online disinhibition effect (Briggle, 2008; Di Gennaro \& Dutton, 2007; Tang, 2010).

The online disinhibition effect also provides options for communication and self-expression among people who would normally be reluctant to disclose. These include people who are typically inhibited or shy (Amichai-Hamburger, 2007; Saunders \& Chester, 2008), introverted or neurotic (Amichai-Hamburger, Wainapel, \& Fox, 2002; Orchard \& Fullwood, 2010), socially phobic (Carlbring, Gunnarsdóttir, Hedensjö, Ekselius, \& Furmark, 2007), or lonely (Whitty \& McLaughlin, 2007), people who stutter (Stoudt \& Ouellette, 2004), individuals with impaired hearing (Barak \& Sadovsky, 2008), and those who are socially stigmatized (McKenna \& Seidman, 2005; McKenna, 2008). Cyberspace reduces the consequences of negative social interactions (the computer can be turned off). This allows people to express themselves with greater ease and freedom than they would otherwise (Amichai-Hamburger, 2007; AmichaiHamburger, McKenna, \& Samuel-Azran, 2008; Seidman, 2014).

Nevertheless, empirical studies reveal inconsistent findings about the role and the influence of online selfdisclosure. For example, it was found that while people with low self-esteem recognize the benefits of selfdisclosure on Facebook, they refrain from revealing their identity (Forest \& Wood, 2012). Others state that although many nonverbal cues are absent on Facebook, Facebook users, for the most part, have confidence in the person to whom they intimately self-disclose, so self-disclosure is dependent upon perceived trust (Sheldon, 2009). In contrast, Park, Jin and Jin (2011) found that, unlike in FtF situations, the degree of intimacy achieved on Facebook is not directly related to the conscious intent at selfdisclosure, but rather to the amount and frequency of interactions. So, further exploration on the factors affecting online self-disclosure is needed.

Benign online disinhibition: Prosocial behavior. Another aspect of the benign online disinhibition effect is its impact on initiating positive interpersonal interactions, in "one-to-many" settings. Amichai-Hamburger, Kingsbury, and Schneider (2012) noted, for example, that in the "one-to-many online environments, friends may offer protection against aggressors, coming to the defense of their peers by way of retaliatory posts (p. 36)." While in general the notion of "retaliation" connotes behaviors more aligned with toxic disinhibition, in the context of defending others against aggressors, it can be considered a behavior associated with the benign effects of disinhibition. Since people feel less inhibited when online, they also do not hesitate to protest when they notice a case of injustice or to express their support of a victim of such behaviors. It has been shown, for instance, that cyberspace bystanders may effectively be employed to reduce different kinds of online aggression incidents (Bastiaensens et. al, 2014; Macháčková, Dedkova, Sevcikova, \& Cerna, 2013; Palasinski, 2012). Thus, it seems that the online disinhibition effect may lead to closer or more involved interpersonal connections and sometimes more meaningful prosocial actions.

The social effects of benign online disinhibition may be expressed in attempts to help others. Typically, people engaged in online activities are prepared to ask and offer each other assistance and advice in 
various subjects. Noticeable examples of online prosocial behaviors include participation in online support groups, counseling, volunteerism, philanthropy, provision of helpful information, and e-mentoring (Morahan-Martin, \& Schumacher, 2003; Panopoulos \& Sarri, 2013; Shim, Cappella, \& Han, 2011; Wright \& Li, 2011).In cases involving the need for urgent emotional support (e.g., individuals contemplating suicide), the effect of online disinhibition has the advantage of establishing interpersonal relationships more quickly than in offline environments and thus the process that leads to self-disclosure is accelerated (Barak \& Suler, 2008; Suler, 2008). The research regarding the factors affecting online prosocial behavior is scarce, and therefore there is a need for additional investigation.

\section{Factors that Foster Online Disinhibition}

The online disinhibition effect is attributed to the unique nature of cyberspace. Previous studies have referred to situation-specific factors that appear to impact the online disinhibition effect, including anonymity, invisibility, asynchronicity, textuality, and absence of eye contact, in addition to personalityrelated factors (cf. Joinson, 2001b, 2007; Suler, 2004). Findings of a study that examined the interactions between dyads of college-age students in a variety of manipulated conditions demonstrated that anonymity, invisibility, and absence of eye contact played major and significant roles in inducing the negative online disinhibition effect (Lapidot-Lefler \& Barak, 2012). Other factors that may reduce inhibitions include online sub-cultures' norms and users' individual characteristics. For example AmichaiHamburger et al. (2002) examined how users' personality affect online social interaction in comparison to FtF interactions. They found that, on the Internet, introverted people behaved in ways that would be described as extraverted offline. However, to date, no previous study, to the best of our knowledge, has examined the factors that lead specifically to benign online disinhibition. This paper will specifically examine three online situational factors-anonymity, invisibility, and lack of eye contact-on inducing selfdisclosure and prosocial behaviors as expressions of benign online disinhibition.

Unidentifiability and anonymity in online disinhibition. Anonymity-considered a major determinant of disinhibited behavior-refers to the condition of being unknown to others in terms of staying incognito to avoid personal identification. Although the concept of anonymity as a research construct has been discussed and examined for more than a decade (e.g., Anonymous, 1998; Scott, 1999), it seems that a misperception regarding the concept still exists. In an attempt to broaden the concept of anonymity we chose to refer to the unidentifiability aspect of anonymity rather than namelessness. That is, we argue that in addition to being nameless, a major-actually crucial-aspect of anonymity should focus on the unidentifiability factor which refers to the condition of being unknown to online partners by concealing identifying personal details, such as gender, weight, age, occupation, ethnic origin and residential location. Online unidentifiability, which contains the component of anonymity, would even make it possible to use real names, as long as other identifying details remain concealed. Conversely, in a FtF encounter, people may avoid revealing their names and yet can be identified by means of their looks alone or some other important personal feature (Bargh, Fitzsimons, \& McKenna, 2003; Chester \& Bretherton, 2007). Identifiability, furthermore, may affect a person's own behaviors and feelings even more than perceiving the identity-enabled cues of others (Tanis \& Postmes, 2007). Another implication of unidentifiability, particularly in computer-mediated social situations, could result in reduced willingness to cooperate (e.g. in building collaborative knowledge with wikis) (Cress \& Kimmerle, 2008; Kimmerle, Cress, \& Hesse, 2007).

In addition, the anonymity and unidentifiability afforded by the Internet may reduce inhibitions that stem from self-awareness and social anxiousness, resulting in increased social interactions and a greater likelihood of forming close and friendly online companionship (Bareket-Bojmel \& Shahar, 2011; MorahanMartin \& Schumacher, 2003). The perception of anonymity and unidentifiability over the Internet gives the user a sense of control over the degree of self-disclosure, in terms of extent, time, and place, which leads to heightened intimacy and openness (Bareket-Bojmel \& Shahar, 2011).

Several studies have suggested that anonymity is a main factor in inducing both benign and toxic online disinhibition effects (e.g., Christopherson, 2007; Fullwood, 2015; Whitty \& Joinson, 2009). However, based on their review of the literature, Wodzicki, Schwämmlein, Cress and Kimmerle (2011) concluded that individual differences among online group members, and the purpose of their participation, interacted with anonymity to affect participants' information-sharing behavior. This implies that the effect of anonymity might not be general, but moderated by other factors. In a quantitative content analysis of personal journal blogs Hollenbaugh and Everett (2013) found that both visual and discursive anonymity actually led to less self-disclosure. An earlier study by Qian and Scott (2007), however, found that visual anonymity led to more disclosure, while discursive anonymity was related less self-disclosure. In analyzing samples of journal-type blogs, Ko (2013) concluded that bloggers' level of self-disclosure was related mainly to their continuous habit of writing and to their perceived personal benefits. 
These inconsistent findings indicate that further investigation is required in order to outline the role of anonymity, and its moderating factors, in inducing online disinhibition. The current study considers whether the distinction between online unidentifiability and online anonymity could help illuminate our understanding of the factors that lead to benign online disinhibition. Although not an immediate objective of this study, the question of whether factors that contribute to the benign disinhibition effect are the same as those that contribute to the toxic disinhibition effect is an additional point of interest.

Invisibility and online disinhibition. Invisibility has been considered as one of the major factors impacting the online disinhibition effect (Joinson, 2001b, 2007; Suler, 2004). Even though anonymity and invisibility are clearly related, these are two distinct variables. Given that computer-mediated communication usually involves invisibility-as most online interpersonal communication is textual-invisibility fosters a unique form of social presence that is defined by the degree of perception, awareness, recognition, or acknowledgement of others. Thus, for example, in a forum that lists the attendees, it is possible to purposely remain socially invisible, while one's username (which may be one's real name-allowing full disclosure, or an alias-allowing for anonymity) appears on the list. Similarly, some forums show a visual image next to the username, which can be an untouched photograph (with varying perspectives, e.g., close-up, profile, entire body) or a specially-designed avatar that is intended to convey something somewhat more personal than an iconic image. Thus, cyberspace allows users to control their levels of social presence (thus, their degree of intimacy) and to control the amount and duration of visibility or invisibility during social interactions. Invisibility, like anonymity, can be used to reduce numerous irrelevant stereotypes and prejudices, such as those related to gender, age, ethnicity and physical attributes. However, it remains unclear whether its effects on the phenomenon of online disinhibition are also similar to those of anonymity.

Online invisibility has been cited as a factor that accelerates the inducement of the online disinhibition effect (e.g., Bregman \& Haythornthwaite, 2003; Lea, Spears, \& Watt, 2007). For instance, Turkle (2011) found that during online communications, people presented themselves in more glowing terms when faced with an image that most resembled a three-dimensional face, compared to their responses during textonly online communications. Tourangeau, Couper and Steiger (2003) varied features of the interface in two Web surveys and a telephone survey. They found that posting photos of surveyors decreased willingness to reply to sensitive questions, compared to the responses to the same survey without such photos, while the use of a telephone survey or an audio-enhanced online survey yielded similar results. This suggests that invisibility can increase the inducement of online disinhibition. Hollenbaugh and Everett (2013), however, found that use of personal pictures actually increased the level of bloggers' selfdisclosure and thus can lead to more intimate, less superficial relationships. Similarly, a qualitative analysis of YouTube videos (Misoch, 2015) suggested that self-disclosure was not related to visual anonymity as visible as well as invisible people similarly tended to disclose information. The conflicting findings suggest that research systematically examining the effects of invisibility, anonymity and their interaction, is needed.

Eye contact and online disinhibition. While it may be claimed that the use of Web cameras during online social interactions effectively eliminates the factor of invisibility, Walther (2007) suggested that the purpose of webcam use is not to convey visual clues from the facial area, but rather to assess general emotional states. For example, with a webcam, it may be possible to discern whether the person sitting in front of you agrees with what you are saying or whether he or she is feeling bored. However, according to Walther (2007), the camera cannot provide sufficient information about facial expressions and fails to provide the kind of information normally provided by eye-contact. Thus, the use of a webcam can provide an indication of the general emotional state of the interlocutor, but it does not necessarily ensure that more subtle communication features can also be captured by the camera or detected by an interlocutor. While the variable 'visibility' represents the acknowledgement of the social presence of others, the 'eye contact' variable represents more subtle communication features. Therefore, in examining the factors that can influence online disinhibition, there is a need to treat visibility and eye contact as separate variables.

Eye contact, or gaze, was found to play an important role in interpersonal communications, mainly in providing nonverbal information about the interlocutor, enabling expressions of intimacy and selfdisclosure, and supporting social control (Kleinke, 1986; Macdonald \& Tatler, 2013; Rigato \& Farroni, 2013; Senju \& Johnson, 2009). Also, eye contact was found to enhance prosocial behaviors by improving information transfer, as it facilitates turn taking and helps manage interruptions, overlaps, and pauses (Boyle, Anderson, \& Newlands, 1994; Halbe, 2012; Mathews, Fox, Yiend \& Calder, 2003). Nevertheless, the effects of eye contact on interpersonal communications are not fully clear. Several studies found gender differences regarding the degree of self-disclosure and the role of eye contact, under different conditions, including with and without eye contact, direct and averted gaze, and with varying levels of eye contact (Bayliss, Pellegrino, \& Tipper, 2005; Jourard \& Friedman, 1970; Pönkänen, Alhoniemi, Leppänen, 
\& Hietanen, 2011; Stevens, Rice, \& Johnson, 1986). In offline encounters, studies found that reduced levels of eye contact increased the duration of self-disclosure (Siegman \& Reynolds, 1983), and conversely, increased levels of eye contact between children and adults had a detrimental effect on the establishment of relationships (Rotenberg et al., 2003). Our recent study which compared the effects of eye contact, invisibility, and anonymity on toxic online disinhibition found that the absence of eye contact was the only factor with a major effect on inducing flaming and aggressive behavior (Lapidot-Lefler \& Barak, 2012). Given these findings, the effects of eye contact (or its absence) on the quality and intimacy of online interpersonal experience, merits more focused consideration.

\section{Research Goals and Hypotheses}

The goal of the current study was to investigate, under controlled conditions, the effects of participants' anonymity, invisibility, and lack of eye contact on self-disclosure and prosocial behaviors as indicators of benign online disinhibition. We hypothesized that these factors would lead to greater self-disclosure and prosocial behaviors. We also expected to find significant additive interaction effects among these factors on self-disclosure and prosocial behavior. In addition, based on previous research, we hypothesized that anonymity (independently and in interaction with the other factors) would show the strongest effects, followed by invisibility and then by the lack of eye contact. On a theoretical level, our aim was to achieve a better understanding of the complexity of the online sense of unidentifiability and its relationship with benign online disinhibition.

\section{Method}

\section{Participants}

The study included 144 participants (72 men and 72 women) who were undergraduate students in two Israeli higher education institutes. Participants' age ranged from 19-40 $(M=24.57 ; S D=3.17)$ years. Participants were recruited by means of advertisements which specified the time required for the experiment and the compensation offered. Exclusion criteria included lack of basic computer skills and no previous experience with online chat programs, lack of written verbal fluency, and failure to establish eye contact (as assessed in the course of a preliminary interview).

\section{Manipulation}

Participants were presented with a dilemma to be debated in dyads through online chat. We employed the "kidney transplant dilemma." A pilot study conducted with Israeli participants found that, of the five dilemmas tested, the "kidney transplant" dilemma aroused the largest number of verbal and behavioral expressions associated with benign online disinhibition. This outcome contrasted with findings obtained with other populations, for whom this dilemma induced toxic disinhibition.

The "kidney transplant dilemma" is comprised of two parts. In the first part of the assignment, participants needed to agree on whom to donate a single available kidney out of nine possible fictional candidates who all needed a kidney transplant. Each candidate was described briefly (e.g., a mother of six young children). In the second part of the assignment each dyad was required to decide which of the two of them, if both of them badly needed a kidney transplant, should receive the kidney. Thus, this part required each participant to convince his (or her) partner that the kidney would be donated to him (or her), or to concede and let the partner have the kidney.

Manipulation of the independent variables (i.e., anonymity, visibility, and lack of eye contact) was conducted by changing the experimental conditions. To this end, a three way experimental factorial design was employed, each consisting of two conditions, creating a 2 (anonymity vs. no-anonymity) $\times 2$ (visibility vs. invisibility) x 2 (eye contact vs. absence of eye contact) design. Consequently, eight combinations of the experimental variables were examined, with each cell containing pairs of 18 participants.

Anonymity was guaranteed by assigning the participants random aliases only, with no further individual identification details. Conversely, non-anonymous participants were assigned a list of personal fictional identifiers, presented in a preset order, as follows: first name, surname, gender, age, address, major field of study, and job possessed if employed.

Visibility was maintained by employing a webcam that afforded each participant a side view of his or her partner's upper body. Conversely, complete invisibility was maintained by the absence of such a camera. 
Eye contact was maintained by employing an additional webcam situated on the computer monitors and adjusted to capture the eyes and a portion of the forehead of the individual participants. Partners were asked to maintain eye contact throughout the experiment. In this manner, the experimental conditions were set to control for any additional non-verbal inputs such as head movements. Conversely, lack of eye contact was maintained by the absence of this camera.

In accordance with the combination of variables examined, none, one, or two cameras were employed: for visibility with eye contact, for example, partners could view each other's upper bodies through one camera while maintaining eye contact through the other. For invisibility with eye contact, only the camera that afforded a view of the participants' gaze was employed.

\section{Measures}

Self-disclosure. Online self-disclosure can be assessed in terms of the length and depth of the disclosure. The length of the disclosure can be measured by a word count (Joinson \& Paine, 2007), whereas the depth of the disclosure, expressed in terms of its intensity and scope, is measured in three layers: the peripheral layer relates to personal biographical information; the mediating layer relates to attitudes, values and opinions (revealing one's thoughts); and the core layer relates to personal beliefs, needs and fears (revealing one's emotions; Altman \& Taylor, 1973).

In the current study, self-disclosure was measured in three ways:

(a) Expert judges' analysis of the text, regarding self-disclosure of information, thoughts and emotions. This was based on self-disclosure models (Joinson, 2001a; Joinson \& Paine, 2007; Omarzu, 2000) and an adaptation of the Rating Scale for Self-disclosure (Vondracek \& Vondracek, 1971), which measures selfdisclosure among adolescents. The inter-rater agreement in studies that used this tool (Shechtman, Hiradin, \& Zina, 2003) found it to be reliable (kappa coefficient 0.95-0.99). The tool was further adapted and used to measure online self disclosure among an adult population in Israel. Inter-rater agreement examined in a previous study (Barak \& Gluck-Ofri, 2007) was satisfactory (kappa coefficient 0.50-0.70). In addition, the adapted tool integrated certain parameters from the Self-Disclosure Index (SDI; Miller, Berg, \& Archer, 1983). The experts were instructed to evaluate the degree of self disclosure on a 3-point Likert-like scale, whereby $0=$ no self-disclosure; $1=$ low degree of self disclosure; $2=$ high degree of self disclosure. In the current study, inter-rater agreement was high according to Kendall's W: self-disclosure of information (0.86), thoughts (0.72) and emotions (0.77).

(b) Textual analysis of self-disclosure. In order to obtain an objective measure of self-disclosure, prespecified words and expressions in the chat-session transcripts were counted (and verified by two trained counters). Consistent with previous studies (Derlega \& Berg, 1987; Joinson, 2001a; Waring, 1990; Barak \& Gluck-Ofri, 2007), the category of words and expressions indicative of self-disclosure included nouns and verbs that expressed emotion, as well as words that did not convey emotion, but contained the firstperson declension in either a conjugated verb or a possessive noun or adjective. Self-disclosing frequencies ranged from 7 to 127 (across all participants).

(c) Self reported self-disclosure was based on Leung's questionnaire (2002) regarding self-disclosure in online chat. The questionnaire included 19 items, with responses rated on a scale of 1 to 5 ( $1=$ totally disagree; 5 = totally agree). The sum of responses constituted the self-reported self-disclosure score. In the current study, the questionnaire's Cronbach's alpha coefficient was found to be 0.76 . A total selfdisclosure score was constructed based on factor analysis-based single factor scores of all self-disclosure measures. The self-disclosure score was obtained by summing the individual scores of the variables, after multiplying them by the factor analysis coefficients. The actual range of the composite scores was 32.88 132.40 .

Prosocial behavior. In the current study, prosocial behavior was measured in three ways: (a) Expert judges' analysis of participants' chat text. Experts were instructed to evaluate the degree of prosocial behavior on a 3-point Likert scale, whereby $0=$ no expressions of prosocial behaviors at all; $1=$ low degree of expressions of prosocial behaviors; 2 = high degree of expressions of prosocial behaviors, on three scales: helping others, complimenting the chat partner, and contributing to positive atmosphere. Inter-rater agreement was assessed using Kendall's coefficient $W$ and was found to be high: $0.92,0.92$ and 0.83 , for helping others, complimenting, and positive atmosphere, respectively; (b) Textual analysis of prosocial behavior. This was performed by counting pre-specified words and expressions in the transcripts of the online chat sessions. The tallies were obtained and verified by two trained counters. Prosocial behavior was determined by counting words and expressions that expressed a positive behavior 
intended for the benefit of the interlocutor, according to the following categories: intent to help the other (e.g., "you should try..."); complimenting the other (e.g., "you're so nice, this situation is very pleasant"); and expressions indicating a positive social or amicable atmosphere (e.g., "thanks for agreeing," "that's a good idea," "I'm sorry to hear that"); (c) Self report of prosocial behavior was based on two items in Leung's questionnaire (2002) regarding self-disclosure in online chat ("I helped the person I talked to and $\mathrm{s} /$ he felt it," "I helped the person I talked to without him/her noticing"). Responses were rated on a scale of 1 to 5 ( $1=$ totally disagree; $5=$ totally agree). Correlation between the items was $0.74,(p<.001)$. The sum of responses constituted the self-reported prosocial behavior score. A total prosocial behavior score was constructed based on a factor analysis of all prosocial behavior measures. The factor analysis based single factor scores was conducted with Eigenvalue greater than 1 . Total prosocial score ranged between 2.08 and 30.28 .

Both self-disclosure and prosocial behavior were measured for each individual participant and not for dyads.

\section{Procedure}

To avoid FtF encounters prior to the beginning of the experiment, participants were asked to arrive at the location of the experiment ten minutes apart. Each participant was randomly assigned a partner; partners were randomly assigned into an equal number of male-male, male-female, and female-female dyads. Dyad partners were seated in separate rooms, which were identical in terms of size, illumination, and background.

The participants were unaware of the purpose of the study; they were told it was to examine how unacquainted individuals use online chat to discuss different subjects. Participants assigned to the eye contact group received special instructions to ensure they would establish eye contact with their partners. Actual eye contact was monitored by experimenters in real-time to ensure the validity of this condition.

Communication within dyads was initiated by presenting them with the dilemma for discussion. Participants were asked to discuss the dilemma through the use of textual chat software and attempt to come up with agreed-upon solutions. Participants were told they had unlimited time available for the discussion, that they must reach agreements with their respective partners, and that they should direct the discussion in such a way as to convince their respective partners to concede. These instructions were given in order to ensure that participants would engage in a dynamic discussion with their partners and to induce in them a drive to win.

The participants were told that there was no time limit on this task. Most of the interactions lasted about 40-60 minutes. However, after an hour and a half, participants who had not reached a decision were asked to stop the activity. Once the debate ended, participants were asked to fill out the self-report questionnaire and a form that provided personal details. Participants were asked to refrain from discussing either the experiment or the facility in which it had taken place with others, in order to prevent any leaking of the experimental procedures.

\section{Results}

\section{Self-Disclosure}

Table 1 presents the means and standard deviations of the self-disclosure measures in the eight experimental conditions.

A MANOVA for the effects of the five measures of self-disclosure (i.e., self-report, experts' evaluations, and number of first-person expressions) by anonymity, invisibility, lack of eye contact was conducted. All main and interaction effects were found to be nonsignificant: for anonymity $F(5,132)=1.11, p>.05, \eta^{2}$ $=.04)$, invisibility $\left.F(5,132)=0.60, p>.05, \eta^{2}=.02\right)$, eye contact $\left(F(5,132)=1.70, p>.05, \eta^{2}=.06\right)$, anonymity $\mathrm{x}$ invisibility $\left.F(5,132)=1.75, p>.05, \eta^{2}=.06\right)$, invisibility $\mathrm{x}$ eye contact $F(5,132)=1.62, p>$ $\left..05, \eta^{2}=.06\right)$, anonymity $x$ eye contact $F(5,132)=0.63, p>.05, \eta^{2}=.02$ ), and anonymity $x$ invisibility $x$ eye contact $\left.F(5,132)=1.38, p>.05, \eta^{2}=.05\right)$. Due to the exploratory nature of the study, univariate analyses were cautiously examined too. These univariate analyses revealed several significant differences, which should be interpreted with caution. These analyses revealed that (a) the interaction between anonymity and invisibility had a significant effect on the disclosure of emotions reflected in chat text $\left(F(1,136)=3.14, p<.05, \eta^{2}=.02\right)$. It was found that text-based disclosure of emotions was higher when anonymity was combined with invisibility $(M=0.70)$ than with visibility $(M=0.46, F(1,136)=2.37$, 
Table 1. Means and Standard Deviations of Self-Disclosure Scores by Situational Factors.

\begin{tabular}{|c|c|c|c|c|c|c|c|c|c|c|}
\hline \multirow[b]{2}{*}{ Anonymity } & Visibility & \multicolumn{2}{|l|}{ Yes } & \multirow[b]{2}{*}{ Total } & \multicolumn{3}{|l|}{ No } & \multicolumn{3}{|l|}{ Total } \\
\hline & Eye Contact & Yes & No & & Yes & No & Total & Yes & No & Total \\
\hline \multicolumn{11}{|c|}{ Self-reports } \\
\hline \multirow{3}{*}{ Yes } & $M$ & 62.39 & 63.06 & 62.72 & 62.97 & 63.67 & 63.32 & 62.68 & 63.36 & 63.02 \\
\hline & $S D$ & 8.38 & 11.02 & 9.66 & 6.69 & 8.62 & 7.61 & 7.48 & 9.75 & 8.64 \\
\hline & $M$ & 61.67 & 60.67 & 61.17 & 64.35 & 61.06 & 62.71 & 63.01 & 60.86 & 61.93 \\
\hline No & $S D$ & 8.49 & 10.58 & 9.47 & 8.77 & 8.86 & 8.72 & 8.62 & 9.62 & 9.13 \\
\hline \multirow{2}{*}{ Total } & $M$ & 62.03 & 61.86 & 61.94 & 63.66 & 62.36 & 63.01 & 62.84 & 62.11 & 62.48 \\
\hline & $S D$ & 8.33 & 10.71 & 9.53 & 7.72 & 8.72 & 8.20 & 8.01 & 9.70 & 8.87 \\
\hline \multicolumn{11}{|c|}{ Revealed Information } \\
\hline \multirow{2}{*}{ Yes } & $M$ & 1.22 & 1.38 & 1.30 & 1.43 & 1.42 & 1.42 & 1.33 & 1.40 & 1.36 \\
\hline & $S D$ & 0.79 & 0.79 & 0.78 & 0.74 & 0.82 & 0.77 & 0.76 & 0.79 & 0.77 \\
\hline \multirow{2}{*}{ No } & $M$ & 1.33 & 1.28 & 1.31 & 1.25 & 1.74 & 1.49 & 1.29 & 1.51 & 1.40 \\
\hline & $S D$ & 0.76 & 0.62 & 0.68 & 0.69 & 0.52 & 0.65 & 0.72 & 0.61 & 0.67 \\
\hline \multirow{2}{*}{ Total } & $M$ & 1.28 & 1.33 & 1.30 & 1.34 & 1.58 & 1.46 & 1.31 & 1.45 & 1.38 \\
\hline & $S D$ & 0.76 & 0.70 & 0.73 & 0.71 & 0.70 & 0.71 & 0.73 & 0.70 & 0.72 \\
\hline \multicolumn{11}{|c|}{$\underline{\text { Revealed Thoughts }}$} \\
\hline \multirow{2}{*}{ Yes } & $M$ & 1.86 & 1.68 & 1.77 & 1.60 & 1.71 & 1.65 & 1.73 & 1.69 & 1.71 \\
\hline & $S D$ & 0.23 & 0.45 & 0.37 & 0.61 & 0.47 & 0.54 & 0.48 & 0.46 & 0.46 \\
\hline \multirow{2}{*}{ No } & $M$ & 1.69 & 1.47 & 1.58 & 1.53 & 1.67 & 1.60 & 1.61 & 1.57 & 1.59 \\
\hline & $S D$ & 0.38 & 0.50 & 0.45 & 0.51 & 0.38 & 0.45 & 0.45 & 0.45 & 0.45 \\
\hline \multirow{2}{*}{ Total } & $M$ & 1.78 & 1.58 & 1.68 & 1.56 & 1.69 & 1.63 & 1.67 & 1.63 & 1.65 \\
\hline & $S D$ & 0.32 & 0.48 & 0.42 & 0.55 & 0.42 & 0.50 & 0.46 & 0.45 & 0.46 \\
\hline \multicolumn{11}{|c|}{$\underline{\text { Revealed Emotions }}$} \\
\hline \multirow{2}{*}{ Yes } & $M$ & 0.40 & 0.51 & 0.46 & 0.64 & 0.76 & 0.70 & 0.52 & 0.64 & 0.58 \\
\hline & $S D$ & 0.50 & 0.63 & 0.57 & 0.76 & 0.76 & 0.75 & 0.65 & 0.70 & 0.67 \\
\hline \multirow{2}{*}{ No } & $M$ & 0.51 & 0.74 & 0.63 & 0.36 & 0.58 & 0.47 & 0.44 & 0.66 & 0.55 \\
\hline & $S D$ & 0.55 & 0.83 & 0.70 & 0.58 & 0.68 & 0.63 & 0.56 & 0.75 & 0.67 \\
\hline \multirow{2}{*}{ Total } & $M$ & 0.46 & 0.63 & 0.54 & 0.50 & 0.67 & 0.59 & 0.48 & 0.65 & 0.56 \\
\hline & $S D$ & 0.52 & 0.74 & 0.64 & 0.68 & 0.71 & 0.70 & 0.60 & 0.72 & 0.67 \\
\hline \multicolumn{11}{|c|}{ First-person Expressions } \\
\hline \multirow{2}{*}{ Yes } & $M$ & 30.22 & 30.39 & 30.31 & 27.67 & 45.94 & 36.81 & 28.94 & 38.17 & 33.56 \\
\hline & $S D$ & 16.12 & 14.59 & 15.15 & 16.57 & 34.96 & 28.51 & 16.17 & 27.55 & 22.91 \\
\hline \multirow{2}{*}{ No } & $M$ & 29.56 & 33.89 & 31.72 & 21.50 & 29.22 & 25.36 & 25.53 & 31.56 & 28.54 \\
\hline & $S D$ & 16.03 & 19.05 & 17.49 & 5.88 & 16.93 & 13.09 & 12.58 & 17.92 & 15.67 \\
\hline Totol & $M$ & 29.89 & 32.14 & 31.01 & 24.58 & 37.58 & 31.08 & 27.24 & 34.86 & 31.05 \\
\hline Tulal & $S D$ & 15.85 & 16.82 & 16.26 & 12.65 & 28.37 & 22.77 & 14.49 & 23.31 & 19.72 \\
\hline
\end{tabular}

Note: $n=18$ per cell

$p<.05, \eta^{2}=.02$ (; yet, the combination of non-anonymity with either visibility or invisibility did not affect the disclosure of emotions $(F(1,136)=0.94, p>.05$. (b) the dependent variable of text-based firstperson expressions was significantly affected by eye contact condition $\left(F(1,136)=5.75, p<.01, \eta^{2}=\right.$ $.04)$. In the condition of lack of eye contact the number of first-person expressions $(M=34.86)$ was higher than when eye contact was enabled $(M=27.24)$. (c) first-person expressions were significantly 
affected by the interaction of anonymity and invisibility $\left(F(1,136)=4.09, p<.05, \eta^{2}=.03\right)$, as well as by the interaction of invisibility and lack of eye contact $\left(F(1,136)=2.86, p<.05, \eta^{2}=.02\right)$. The condition of invisibility combined with anonymity rendered more first-person expressions $(M=36.81)$ than when combined with non-anonymity $\left(M=25.36, F(1,136)=6.48, p<.01, \eta^{2}=.05\right)$. However, the combination of visibility with either anonymity or non-anonymity did not affect the prevalence of firstperson expressions $(F(1,136)=0.10, p>.05)$. Furthermore, there were more first-person expressions when invisibility was combined with lack of eye contact $(M=37.58)$ than when eye contact was enabled $\left(M=24.58, F(1,136)=8.36, p<.01, \eta^{2}=.06\right)$, but in the condition of visibility, the presence or absence of eye contact had no effect on first-person expressions $(F(1,136)=0.25, p>.05)$.

Table 2 gives the means and standard deviations of the composite self-disclosure score (an aggregate of all self-disclosure measures, constructed on the basis of a factor analysis of all self-disclosure behavior measures) by the experimental conditions. Its range was 32.88-132.40, with a total mean of $55.62(S D=$ 17.37).

Table 2. Means and Standard Deviations of Composite Self-Disclosure by Situational Factors $(N=144)$.

\begin{tabular}{|c|c|c|c|c|c|c|c|c|c|c|}
\hline \multirow[b]{2}{*}{ Anonymity } & \multirow{2}{*}{$\begin{array}{l}\text { Visibility } \\
\text { Eye Contact }\end{array}$} & \multicolumn{3}{|l|}{ Yes } & \multicolumn{3}{|l|}{ No } & \multicolumn{3}{|l|}{ Total } \\
\hline & & Yes & No & Total & Yes & No & Total & Yes & No & Total \\
\hline \multirow{2}{*}{ Yes } & $M$ & 54.82 & 55.33 & 55.08 & 53.20 & 68.27 & 60.74 & 54.01 & 61.80 & 57.91 \\
\hline & $S D$ & 15.31 & 13.48 & 14.22 & 15.21 & 29.34 & 24.27 & 15.06 & 23.44 & 19.95 \\
\hline \multirow{2}{*}{ No } & $M$ & 54.02 & 57.02 & 55.52 & 48.54 & 53.77 & 51.15 & 51.28 & 55.39 & 53.34 \\
\hline & $S D$ & 14.22 & 17.90 & 16.00 & 4.98 & 15.58 & 11.70 & 10.86 & 16.62 & 14.09 \\
\hline \multirow{2}{*}{ Total } & $M$ & 54.42 & 56.18 & 55.30 & 50.87 & 61.02 & 55.94 & 52.64 & 58.60 & 55.62 \\
\hline & $S D$ & 14.57 & 15.64 & 15.03 & 11.41 & 24.29 & 19.52 & 13.11 & 20.43 & 17.37 \\
\hline
\end{tabular}

Note: Range: 32.88-132.40

ANOVA results for the composite self-disclosure score revealed that eye contact had significant effect $\left(F(1,136)=4.44, p<.05, \eta^{2}=.03\right)$ so that the total self-disclosure score was higher in the absence of eye contact $(M=58.60)$ than with eye contact $(M=52.64)$. In addition, the interaction between anonymity and invisibility $\left(F(1,136)=3.15, p<.05, \eta^{2}=.02\right)$ was significant, revealing that the combination of invisibility with anonymity rendered a higher total self-disclosure score $(M=60.74)$ than when combined with non-anonymity $(M=51.15)\left(F(1,136)=5.75, p<.01, \eta^{2}=.04\right)$. However, in the condition of visibility, the presence or absence of anonymity had no effect on the total self-disclosure score $(F(1,136)=0.01, p>.05)$. The ANOVA was non-significant for anonymity $(F(1,136)=2.62, p>$ $.05)$, invisibility $(F(1,136)=0.05, p>.05)$, invisibility by lack of eye contact $F(1,136)=2.21, p>.05)$, anonymity by lack of eye contact $F(1,136)=0.42, p>.05)$, and anonymity by invisibility by lack of eye contact $F(1,136)=1.19, p>.05)$.

\section{Prosocial Behaviors}

Table 3 presents the means and standard deviations of the prosocial measures according to the eight experimental conditions.

As before, the MANOVA for the effects of the five measures of prosocial behaviors (i.e., self-reported prosocial behavior, helping others, complimenting, positive atmosphere, and prosocial expressions) by anonymity, invisibility, lack of eye contact and their interactions was found to be non-significant for all effects. For anonymity $F(5,132)=1.38, p>.05)$, invisibility $F(5,132)=0.35, p>.05)$, lack of eye contact $(F(5,132)=0.18, p>.05)$, anonymity by invisibility $F(5,132)=1.56, p>.05)$, invisibility by lack of eye contact $F(5,132)=0.58, p>.05)$, anonymity by lack of eye contact $F(5,132)=0.34, p>.05)$, and anonymity by invisibility by lack of eye contact $F(5,132)=1.05, p>.05)$. 
Table 3. Means and Standard Deviations of Prosocial Behavior Scores by Situational Factors $(N=144)$.

\begin{tabular}{|c|c|c|c|c|c|c|c|c|c|c|}
\hline \multirow[b]{2}{*}{ Anonymity } & \multirow{2}{*}{$\frac{\text { Visibility }}{\text { Eye Contact }}$} & \multicolumn{3}{|l|}{ Yes } & \multicolumn{3}{|l|}{ No } & \multicolumn{3}{|c|}{ Total } \\
\hline & & Yes & No & Total & Yes & No & Total & Yes & No & Total \\
\hline & \multicolumn{10}{|c|}{ Self-reports } \\
\hline \multirow{2}{*}{ Yes } & $M$ & 5.39 & 5.83 & 5.61 & 5.67 & 5.89 & 5.78 & 5.53 & 5.86 & 5.69 \\
\hline & $S D$ & 1.04 & 1.72 & 1.42 & 1.91 & 1.60 & 1.74 & 1.52 & 1.64 & 1.58 \\
\hline \multirow{2}{*}{ No } & $M$ & 5.78 & 5.11 & 5.44 & 5.39 & 5.94 & 5.67 & 5.58 & 5.53 & 5.56 \\
\hline & $S D$ & 1.48 & 1.81 & 1.66 & 1.33 & 2.07 & 1.74 & 1.40 & 1.96 & 1.69 \\
\hline \multirow{3}{*}{ Total } & $M$ & 5.58 & 5.47 & 5.53 & 5.53 & 5.92 & 5.72 & 5.56 & 5.69 & 5.63 \\
\hline & $S D$ & 1.27 & 1.78 & 1.54 & 1.63 & 1.83 & 1.73 & 1.45 & 1.80 & 1.63 \\
\hline & \multicolumn{10}{|c|}{ Helping Others } \\
\hline \multirow{2}{*}{ Yes } & $M$ & 1.06 & 1.03 & 1.04 & 0.82 & 0.82 & 0.82 & 0.94 & 0.92 & 0.93 \\
\hline & $S D$ & 0.83 & 0.83 & 0.82 & 0.80 & 0.91 & 0.85 & 0.82 & 0.87 & 0.84 \\
\hline \multirow{2}{*}{ No } & $M$ & 0.79 & 0.75 & 0.77 & 1.12 & 1.13 & 1.12 & 0.96 & 0.94 & 0.94 \\
\hline & $S D$ & 0.86 & 0.90 & 0.86 & 0.87 & 0.78 & 0.81 & 0.87 & 0.85 & 0.85 \\
\hline \multirow{3}{*}{ Total } & $M$ & 0.92 & 0.89 & 0.91 & 0.97 & 0.97 & 0.97 & 0.94 & 0.93 & 0.94 \\
\hline & $S D$ & 0.84 & 0.86 & 0.85 & 0.84 & 0.85 & 0.84 & 0.84 & 0.85 & 0.84 \\
\hline & \multicolumn{10}{|c|}{ Complimenting } \\
\hline \multirow{2}{*}{ Yes } & $M$ & 0.49 & 0.78 & 0.63 & 0.47 & 0.54 & 0.51 & 0.48 & 0.66 & 0.57 \\
\hline & $S D$ & 0.79 & 0.88 & 0.84 & 0.79 & 0.88 & 0.82 & 0.78 & 0.87 & 0.83 \\
\hline \multirow{2}{*}{ No } & $M$ & 0.65 & 0.44 & 0.55 & 0.65 & 0.69 & 0.67 & 0.65 & 0.57 & 0.61 \\
\hline & $S D$ & 0.88 & 0.66 & 0.77 & 0.85 & 0.95 & 0.88 & 0.85 & 0.82 & 0.83 \\
\hline \multirow{3}{*}{ Total } & $M$ & 0.57 & 0.61 & 0.59 & 0.56 & 0.62 & 0.59 & 0.57 & 0.61 & 0.59 \\
\hline & $S D$ & 0.83 & 0.78 & 0.80 & 0.81 & 0.91 & 0.85 & 0.81 & 0.84 & 0.82 \\
\hline & \multicolumn{10}{|c|}{ Positive Atmosphere } \\
\hline \multirow{2}{*}{ Yes } & $M$ & 1.49 & 1.64 & 1.56 & 1.33 & 1.22 & 1.28 & 1.41 & 1.43 & 1.42 \\
\hline & $S D$ & 0.57 & 0.56 & 0.56 & 0.72 & 0.73 & 0.72 & 0.64 & 0.68 & 0.66 \\
\hline \multirow{2}{*}{ No } & $M$ & 1.44 & 1.50 & 1.47 & 1.64 & 1.61 & 1.63 & 1.54 & 1.56 & 1.55 \\
\hline & $S D$ & 0.59 & 0.54 & 0.56 & 0.47 & 0.40 & 0.43 & 0.53 & 0.47 & 0.50 \\
\hline \multirow{3}{*}{ Total } & $M$ & 1.47 & 1.57 & 1.52 & 1.49 & 1.42 & 1.45 & 1.48 & 1.49 & 1.48 \\
\hline & $S D$ & 0.57 & 0.55 & 0.56 & 0.62 & 0.62 & 0.62 & 0.60 & 0.58 & 0.59 \\
\hline & \multicolumn{10}{|c|}{ Prosocial Expressions } \\
\hline \multirow{2}{*}{ Yes } & $M$ & 8.11 & 7.28 & 7.69 & 6.28 & 7.39 & 6.83 & 7.19 & 7.33 & 7.26 \\
\hline & $S D$ & 7.38 & 3.79 & 5.80 & 4.46 & 5.18 & 4.80 & 6.08 & 4.47 & 5.30 \\
\hline \multirow{2}{*}{ No } & $M$ & 6.17 & 5.89 & 6.03 & 7.28 & 6.00 & 6.64 & 6.72 & 5.94 & 6.33 \\
\hline & $S D$ & 4.26 & 3.56 & 3.87 & 2.65 & 5.19 & 4.11 & 3.54 & 4.39 & 3.98 \\
\hline \multirow{2}{*}{ Total } & $M$ & 7.14 & 6.58 & 6.86 & 6.78 & 6.69 & 6.74 & 6.96 & 6.64 & 6.80 \\
\hline & $S D$ & 6.02 & 3.69 & 4.97 & 3.65 & 5.16 & 4.44 & 4.95 & 4.45 & 4.69 \\
\hline
\end{tabular}

However, due to the exploratory nature of the study, and the fact that prosocial behavior was assessed using various measures (self-report, expert analysis, and textual analysis) rather than a single measure, univariate analyses were examined. These analyses revealed one significant difference, regarding the variable of intent to help the other $\left(F(1,136)=4.15, p<.05, \eta^{2}=.03\right)$. It was found that non-anonymity combined with invisibility resulted in a higher prevalence of intent to help $(M=1.12)$ than when combined 
with visibility $\left(M=0.77, F(1,136)=3.13, p<.05, \eta^{2}=.02\right)$. Yet, in the condition of anonymity, the presence or absence of visibility did not affect the intent to help $(F(1,136)=1.23, p>.05)$.

Table 4 presents the means and standard deviations of the total prosocial behaviors score, constructed on the basis of a factor analysis of all prosocial behavior measures, according to experimental conditions. Its range was $2.08-30.28$, with a total mean of $10.14(S D=4.55)$.

Table 4. Means and Standard Deviations of Composite Prosocial Behavior by Situational Factors $(N=144)$.

\begin{tabular}{|c|c|c|c|c|c|c|c|c|c|c|}
\hline \multirow[b]{2}{*}{ Anonymity } & \multirow{2}{*}{$\begin{array}{l}\text { Visibility } \\
\text { Eye Contact }\end{array}$} & \multicolumn{3}{|l|}{ Yes } & \multicolumn{3}{|l|}{ No } & \multicolumn{3}{|l|}{ Total } \\
\hline & & Yes & No & Total & Yes & No & Total & Yes & No & Total \\
\hline \multirow{2}{*}{ Yes } & $\mathrm{M}$ & 11.05 & 10.89 & 10.97 & 9.50 & 10.44 & 9.97 & 10.28 & 10.67 & 10.47 \\
\hline & SD & 6.53 & 3.95 & 5.32 & 4.54 & 5.33 & 4.90 & 5.60 & 4.63 & 5.10 \\
\hline \multirow{2}{*}{ No } & $M$ & 9.65 & 9.01 & 9.33 & 10.65 & 9.92 & 10.28 & 10.15 & 9.46 & 9.81 \\
\hline & SD & 4.28 & 3.60 & 3.91 & 2.17 & 5.21 & 3.95 & 3.38 & 4.43 & 3.93 \\
\hline \multirow{2}{*}{ Total } & $\mathrm{M}$ & 10.35 & 9.95 & 10.15 & 10.08 & 10.18 & 10.13 & 10.21 & 10.07 & 10.14 \\
\hline & SD & 5.49 & 3.84 & 4.71 & 3.55 & 5.20 & 4.42 & 4.59 & 4.54 & 4.55 \\
\hline
\end{tabular}

Note: Range: 2.08-30.28

The ANOVA for the total prosocial behaviors score was found non-significant for anonymity $(F(1,136)=$ $0.75, p>.05)$, invisibility $(F(1,136)=0.01, p>.05)$, lack of eye contact $(F(1,136)=0.04, p>.05)$, and their interactions (anonymity by invisibility $F(1,136)=1.61, p>.05$ ), invisibility by lack of eye contact $F(1,136)=0.11, p>.05)$, anonymity by lack of eye contact $F(1,136)=0.49, p>.05)$, and anonymity by invisibility by lack of eye contact $F(1,136)=0.14, p>.05)$.

\section{Discussion}

The aim of the current study was to observe, under controlled conditions, the independent and combined effects of participants' anonymity, invisibility, and eye contact on indicators of benign online disinhibition. The results indicated that these factors, for the most part, did not have a statistically significant effect on the different measures of self- disclosure (self- report of self-disclosure, revealed information, revealed thoughts) and prosocial behavior (self-report of prosocial behavior, complimenting, positive atmosphere, and prosocial expressions).

However, there were two interesting findings regarding disclosure of emotions. First, the interaction between anonymity and invisibility had a significant effect on the dimension of self-disclosure of emotions: disclosure of emotions was higher when anonymity was combined with invisibility than with visibility. Yet, when the inverse conditions were tested, i.e., nonanonymity with either visibility or invisibility, neither of the two combinations had an effect on the disclosure of emotions. The second finding which relates to the interactions between invisibility and eye contact was similar: there were more first-person expressions when invisibility was combined with lack of eye contact than when eye contact was enabled, but in the condition of visibility, the presence or absence of eye contact had no effect on first-person expressions.

It should be noted that the aforementioned findings had low effect sizes and, therefore, should be interpreted with caution. They do seem to suggest that of the three independent variables, the interaction between anonymity and invisibility and the interaction between invisibility and eye contact may influence the benign online disinhibition in terms of disclosure of emotions and first-person expressions.

Despite the paucity of statistically significant findings, the results of the current study do lend some support to the hypothesis that the interactions among the factors would correlate positively with high degrees of self-disclosure. In addition, findings from the current study refuted the hypothesis that anonymity was the strongest predictor of online self-disclosure. This finding contradicts the widely accepted claim that anonymity plays a major role in inducing the online disinhibition effect. One possible explanation for this may be the differences between previous definitions of online anonymity and the definition used in this study. "Anonymity" in previous studies did not take into account other factors in the online environments that might affect one's sense of anonymity, i.e., the presence or absence of eye 
contact and visibility. Given the fact that introducing these factors led to different findings, it seems advisable to continue testing these factors in future studies. Future findings will help determine whether the term anonymity should be adapted to reflect additional parameters that characterize the new virtual reality.

The current study was designed as a continuation of a previous study which focused on the toxic effects of online disinhibition (Lapidot-Lefler \& Barak, 2012). Findings regarding the benign aspects could be compared to those of our previous study. The most salient contrast between the findings is the fact that all multivariate analyses in the current study had non-significant results. This indicates that the benign effects of online disinhibition may be more complex than its toxic effects. Further, the comparison of the results of the two studies suggests that the benign online disinhibition involves factors different from those involved in toxic online disinhibition. More research is required to determine the nature of the contribution of each factor to both toxic and benign disinhibition effects.

The fact that online communication can be characterized by an array of changeable conditions (i.e., with or without any combination of situational factors) suggests that familiar concepts should be re-examined. Certain combinations of the various conditions may create an individual's sense of online unidentifiability and this is what induces perceived disinhibition online. Thus, from a CMC perspective, withholding personal details, which is the narrow definition of anonymity, should not be equated with absence of visibility or with lack of eye contact. Replacing anonymity with this overall sense of online unidentifiability makes it possible to examine the relative contribution of each of these three factors (or relevant others) in different Web applications (e.g., dating sites, shopping sites, learning sites), as well as for different users (e.g., by personality characteristics). Further confirmation of the results of the current study may provide a clear indication that the complexity of interactions between factors associated with benign online disinhibition is greater than among factors associated with the toxic effects of online disinhibition.

The benign manifestations of the online disinhibition effect may have some implications in cyberspace and beyond. Understanding the interactions between the variables can help explain the impact of CMC on the fields of psychotherapy and medicine. Knowing the most effective combination of factors associated with self-disclosure, for example, would enable caregivers to create an optimal environment for the benefit of their patients.

\section{Limitations and Suggestions for Further Study}

It is important to note that the current research employed an experimental design, hence its external validity is limited. Additional research is needed to examine differential and independent effects of anonymity, visibility, and eye-contact under real social situations. Another challenge in the current study is the technical complexity involved in creating eye-contact in webcam communication. The existing technologies do not support the desirable level of eye-contact: usually, webcams and computer screens are positioned in such a way as to render direct eye-contact difficult, since both parties could have problems in achieving mutual ongoing eye-contact (one can either stare directly at the camera or at his/her interlocutor's image on the screen, but not both). Although the solution to this problem is undoubtedly technological, the current study demonstrates that mutual on-going eye contact seems to fulfill an important psychological need. Technological progress in this area could facilitate the development of better, more meaningful eye-contact during computer-mediated communication, and thus attenuate negative online disinhibition.

Future studies should examine the effect of various types of information regarding a person's identity, such as occupation, education, and social status. Our findings suggest a certain direction for further research; however, new and more powerful means for manipulating the setting are needed. The duration of online interactions might also affect the resulting level of disinhibition, since longer conversations might have caused the disinhibition effect to become more pronounced. The average duration of conversations was 40 minutes, in line with practices used in previous studies (Joinson, 2001b; Lapidot-Lefler \& Barak, 2012). While participants were told that they had unlimited time to interact, actual conversations ranged from 20 to 90 minutes. Requiring participants to chat for a minimum of 40 minutes may be advisable, in order to enable a more comprehensive demonstration of online disinhibition.

It is also suggested that future studies that employ a methodology similar to that employed in the current study should examine the results in terms of the dyads, in order to take into account the dependency of the data. Furthermore, while the present study shed some light on the interaction of variables related to positive behavioral disinhibition, additional aspects that might affect this process should be addressed in future studies. Synchronicity, gender and gender matching, as well as variables related to personality or 
identity structure might have influenced the results, and therefore they should be studied both discretely and in combination.

\section{References}

Altman, I., \& Taylor, D. A. (1973). Social penetration: The development of interpersonal relationships. New York: Holt, Rinehart \& Winston.

Amichai-Hamburger, Y. (2007). Personality, individual differences and Internet use. In A. Joinson, K. Y. A. McKenna, T. Postmes, \& U. D. Reips (Eds.), Oxford handbook of Internet psychology (pp. 187-204).

Oxford, UK: Oxford University Press.

Amichai-Hamburger, Y., Kingsbury, M., \& Schneider, B. H. (2012). Friendship: An old concept with a new meaning? Computers in Human Behavior, 29, 33-39. http://dx.doi.org/10.1016/j.chb.2012.05.025

Amichai-Hamburger, Y., McKenna, K. Y. A., \& Samuel-Azran, T. (2008). E-empowerment: Empowerment by the Internet. Computers in Human Behavior, 24, 1776-1789.

http://dx.doi.org/10.1016/j.chb.2008.02.002

Anolli, L., Villani, D., \& Riva, G. (2005). Personality of people using chat: An online research. CyberPsychology \& Behavior, 8, 89-95.

Anonymous (1998). To reveal or not to reveal: A theoretical model of anonymous communication. Communication Theory, 8, 381-407.

Archer, R. L. (1980). Self-disclosure. In D. Wegner \& R. Vallacher (Eds.), The self in social psychology (pp. 183-205). New York: Oxford University Press.

Barak, A. (2007). Phantom emotions: Psychological determinants of emotional experiences on the Internet. In A. Joinson, K. Y. A. McKenna, T. Postmes, \& U. D. Reips (Eds.), Oxford handbook of Internet psychology (pp. 303-329). Oxford, UK: Oxford University Press.

Barak, A., \& Gluck-Ofri, O. (2007). Degree and reciprocity of self-disclosure in online forums. CyberPsychology \& Behavior, 10, 407-417. http://dx.doi.org/10.1089/cpb.2006.9938

Barak, A., \& Sadovsky, Y. (2008). Internet use and personal empowerment of hearing-impaired adolescents. Computers in Human Behavior, 24, 1802-1815.

http://dx.doi.org/10.1016/j.chb.2008.02.007

Barak, A., \& Suler, J. (2008). Reflections on the psychology and social science of cyberspace. In A. Barak (Ed.), Psychological aspects of cyberspace: Theory, research, applications (pp. 1-12). Cambridge, UK: Cambridge University Press.

Bareket-Bojmel, L., \& Shahar, G. (2011). Emotional and interpersonal consequences of self-disclosure in a lived, online interaction. Journal of Social and Clinical Psychology, 30, 732-759.

http://dx.doi.org/10.1521/jscp.2011.30.7.732

Bargh, J. A., Fitzsimons, G. M., \& McKenna, K. Y. A. (2003). The self, online. In S. J. Spencer, S. Fein, M. P. Zanna, \& J. M. Olson (Eds.), Motivated social perception, the Ontario Symposium, volume 9 (pp. 195213). London: Lawrence Erlbaum.

Bastiaensens, S., Vandebosch, H., Poels, K., Van Cleemput, K., DeSmet, A., \& De Bourdeaudhuij, I. (2014). Cyberbullying on social network sites: An experimental study into bystanders' behavioural intentions to help the victim or reinforce the bully. Computers in Human Behavior, 31, 259-271. http://dx.doi.org/10.1016/j.chb.2013.10.036

Bayliss, A. P., Pellegrino, G., \& Tipper, S. P. (2005). Sex differences in eye gaze and symbolic cueing of attention. The Quarterly Journal of Experimental Psychology, 58, 631-650.

http://dx.doi.org/10.1080/02724980443000124 
Ben-Ze'ev, A. (2004). Love online: Emotions on the Internet. Cambridge, UK: Cambridge University Press.

Boyle, E. A., Anderson, A. H., \& Newlands, A. (1994). The effects of visibility on dialogue and performance in a cooperative problem solving task. Language and Speech, 37, 1-20.

Bregman, A., \& Haythornthwaite, C. (2003). Radicals of presentation: visibility, relation, and co-presence in persistent conversation. New Media \& Society, 5, 117-140.

http://dx.doi.org/10.1177/1461444803005001913

Briggle, A. (2008). Real friends: How the Internet can foster friendship. Ethics and Information

Technology, 10, 71-79. http://dx.doi.org/ 10.1007/s10676-008-9160-z

Carlbring, P., Gunnarsdóttir, M., Hedensjö, L., Ekselius, L., \& Furmark, T. (2007). Treatment of social phobia: Randomised trial of Internet-delivered cognitive-behavioural therapy with telephone support. The British Journal of Psychiatry, 190, 123-128. http://dx.doi.org/10.1192/bjp.bp.105.020107

Chester, A., \& Bretherton, D. (2007). Impression management and identity online. The Oxford handbook of Internet psychology , 223-236.

Christopherson, K. M. (2007). The positive and negative implications of anonymity in Internet social interactions: "On the Internet, Nobody Knows You're a Dog." Computers in Human Behavior, 23, 30383056. http://dx.doi.org/10.1016/j.chb.2006.09.001

Cress, U., \& Kimmerle, J. (2008). A systemic and cognitive view on collaborative knowledge building with wikis. International Journal of Computer-Supported Collaborative Learning, 3, 105-122.

http://dx.doi.org/10.1007/s11412-007-9035-z

Di Gennaro, C., \& Dutton, W. H. (2007). Reconfiguring friendships: Social relationships and the Internet. Information, Communication \& Society, 10, 591-618. http://dx.doi.org/10.1080/13691180701657949

Davis, K. (2012). Friendship 2.0: Adolescents' experiences of belonging and self-disclosure online. Journal of Adolescence, 35, 1527-1536. http://dx.doi.org/10.1016/j.adolescence.2012.02.013

Derlega, V. J., \& Berg, J. H. (1987). Self-disclosure: Theory, research, and therapy. New York: Plenum.

Derlega, V. J., Metts, S., Petronio, S., \& Margulis, S. T. (1993). Self-disclosure. Newbury Park, CA: Sage.

Forest, A. L., \& Wood, J. V. (2012). When social networking is not working individuals with low selfesteem recognize but do not reap the benefits of self-disclosure on Facebook. Psychological Science, 23, 295-302. http://dx.doi.org/10.1177/0956797611429709

Fullwood, C. (2015). The role of personality in online self-presentation. In A. Attrill (Ed.), Cyberpsychology (pp. 89-110). Oxford University Press.

Gibbs, J. L., Ellison, N. B., \& Lai, C. (2011). First comes love, then comes Google: An investigation of uncertainty reduction strategies and self-disclosure in Online dating. Communication Research, 38, 70100. http://dx.doi.org/10.1177/0093650210377091

Halbe, D. (2012). "Who's there?" : Differences in the Features of Telephone and Face-to-Face Conferences. Journal of Business Communication, 49, 48-73.

http://dx.doi.org/10.1177/0021943611425238

Hollenbaugh, E. E., \& Everett, M. K. (2013). The effects of anonymity on self-disclosure in blogs: An application of the online disinhibition effect. Journal of Computer-Mediated Communication, 18, $283-302$. http://dx.doi.org/10.1111/jcc4.12008

Jiang, L. C., Bazarova, N. N., \& Hancock, J. T. (2013). From perception to behavior: Disclosure reciprocity and the intensification of intimacy in computer-mediated communication. Communication Research, 40, 125-143. http://dx.doi.org/10.1177/0093650211405313 
Joinson, A. N. (2001a). Knowing me, knowing you: Reciprocal self-disclosure in Internet-based surveys. CyberPsychology \& Behavior, 4, 587-591. http://dx.doi.org/10.1089/109493101753235179

Joinson, A. N. (2001b). Self-disclosure in computer-mediated communication: The role of self-awareness and visual anonymity. European Journal of Social Psychology, 31, 177-192.

http://dx.doi.org/10.1002/ejsp.36

Joinson, A. N. (2007). Disinhibition and the Internet. In J. Gackenbach (Ed.), Psychology and the Internet: Intrapersonal, interpersonal, and transpersonal implications (2nd ed., pp. 75-92). San Diego, CA, US: Academic Press.

Joinson, A. N., \& Paine, C. B. (2007). Self-disclosure, privacy and the Internet. In A. N. Joinson, K. Y. A. McKenna, T. Postmes, \& U. D. Reips (Eds.), Oxford handbook of Internet psychology (pp. 237-252). Oxford, UK: Oxford University Press. http://dx.doi.org/10.1016/j.chb.2007.10.005

Joinson, A. N., Paine, C. B., \& Buchanan, T. (2008). Measuring self-disclosure online: Blurring and nonresponse to sensitive items in web-based surveys. Computers in Human Behavior, 24, 2158-2171.

Jourard, S. M., \& Friedman, R. (1970). Experimenter-subject "distance" and self-disclosure. Journal of Personality and Social Psychology, 15, 278-282. http://dx.doi.org/10.1037/h0029388

Kimmerle, J., Cress, U., \& Hesse, F. W. (2007). An interactional perspective on group awareness: Alleviating the information-exchange dilemma (for everybody?). International Journal of Human-Computer Studies, 65, 899-910. http://dx.doi.org/10.1016/j.ijhcs.2007.06.002

Kleinke, C. L. (1986). Gaze and eye contact: A research review. Psychological Bulletin, 100, 78-100. http://dx.doi.org/10.1037/0033-2909.100.1.78

Ko, H. C. (2013). The determinants of continuous use of social networking sites: An empirical study on Taiwanese journal-type bloggers' continuous self-disclosure behavior. Electronic Commerce Research and Applications, 12, 103-111. http://dx.doi.org/10.1016/j.elerap.2012.11.002

Lapidot-Lefler, N., \& Barak, A. (2012). Effects of anonymity, invisibility, and lack of eye contact on toxic online disinhibition. Computers in Human Behavior, 28, 434-443.

http://dx.doi.org/10.1016/j.chb.2011.10.014

Lea, M., Spears, R., \& Watt, S., E. (2007). Visibility and anonymity effects on attraction and group cohesiveness. European Journal of Social Psychology, 37, 761-773. http://dx.doi.org/10.1002/ejsp.398

Leung, L. (2002). Loneliness, self-disclosure, and ICQ (" I seek you") use. CyberPsychology \& Behavior, 5, 241-251. http://dx.doi.org/10.1089/109493102760147240

Macdonald, R. G., \& Tatler, B. W. (2013). Do as eye say: Gaze cueing and language in a real-world social interaction. Journal of Vision, 13, 6. http://dx.doi.org/10.1167/13.4.6

Macháčková, H., Dedkova, L., Sevcikova, A., \& Cerna, A. (2013). Bystanders' support of cyberbullied schoolmates. Journal of Community \& Applied Social Psychology, 23, 25-36.

http://dx.doi.org/10.1002/casp.2135

Magsamen-Conrad, K., Billotte-Verhoff, C., \& Greene, K. (2014). Technology addiction's contribution to mental wellbeing: The positive effect of online social capital. Computers in Human Behavior, 40, 23-30. http://dx.doi.org/10.1016/j.chb.2014.07.014

Manago, A. M., Taylor, T., \& Greenfield, P. M. (2012). Me and my 400 friends: The anatomy of college students' Facebook networks, their communication patterns, and well-being. Developmental Psychology, 48, 369-380. http://dx.doi.org/10.1037/a0026338

Mathews, A., Fox, E., Yiend, J., \& Calder, A. (2003). The face of fear: Effects of eye gaze and emotion on visual attention. Visual Cognition, 10, 823-835. http://dx.doi.org/10.1080/13506280344000095 
McKenna, K. Y. A. (2008). Influences on the nature and functioning of online groups. In A. Barak (Ed.), Psychological aspects of cyberspace: Theory, research, applications (pp. 228-242). Cambridge, UK:

Cambridge University Press.

McKenna, K. Y. A., \& Seidman, G. (2005). Social identity and the self: Getting connected online. In W. R. Walker \& D. J. Herrmann (Eds.), Cognitive technology (pp. 89-110). Jefferson, NC: McFarland.

Miller, L. C., Berg, J. H., \& Archer, R. L. (1983). Openers: Individuals who elicit intimate self-disclosure. Journal of Personality and Social Psychology, 44, 1234-1244. http://dx.doi.org/10.1037/0022-

3514.44.6.1234

Misoch, S. (2015). Stranger on the internet: Online self-disclosure and the role of visual anonymity. Computers in Human Behavior, 48, 535-541. http://dx.doi.org/ 10.1016/j.chb.2015.02.027

Morahan-Martin, J., \& Schumacher, P. (2003). Loneliness and social uses of the Internet. Computers in Human Behavior, 19, 659-671. http://dx.doi.org/10.1016/S0747-5632(03)00040-2

Omarzu, J. (2000). A disclosure decision model: Determining how and when individuals will self-disclose. Personality and Social Psychology Review, 4, 174-185.

http://dx.doi.org/10.1207/S15327957PSPR0402_05

Orchard, L. J., \& Fullwood, C. (2010). Current perspectives on personality and Internet use. Social Science Computer Review, 28, 155-169. http://dx.doi.org/10.1177/0894439309335115

Palasinski, M. (2012). The roles of monitoring and cyberbystanders in reducing sexual abuse. Computers in Human Behavior, 28, 2014-2022. http://dx.doi.org/10.1016/j.chb.2012.05.020

Panopoulos, A. P., \& Sarri, K. (2013). E-mentoring: The adoption process and innovation challenge. International Journal of Information Management, 33, 217-226.

http://dx.doi.org/10.1016/j.ijinfomgt.2012.10.003

Park, N., Jin, B., \& Jin, S. A. A. (2011). Effects of self-disclosure on relational intimacy in Facebook. Computers in Human Behavior, 27, 1974-1983. http://dx.doi.org/10.1016/j.chb.2011.05.004

Pönkänen, L. M., Alhoniemi, A., Leppänen, J. M., \& Hietanen, J. K. (2011). Does it make a difference if I have an eye contact with you or with your picture? An ERP study. Social Cognitive \& Affective Neuroscience, 6, 486-494. http://dx.doi.org/10.1093/scan/nsq068

Qian, H., \& Scott, C. R. (2007). Anonymity and self-disclosure on weblogs. Journal of Computer-Mediated Communication, 12, 1428-1451. http://dx.doi.org/10.1111/j.1083-6101.2007.00380.x

Reich, S. M., Subrahmanyam, K., \& Espinoza, G. (2012). Friending, IMing, and hanging out face-to-face: Overlap in adolescents' online and offline social networks. Developmental Psychology, 48, 356-368. http://dx.doi.org/10.1037/a0026980

Rigato, S., \& Farroni, T. (2013). The role of gaze in the processing of emotional facial expressions. Emotion Review, 5, 36-40. http://dx.doi.org/10.1177/1754073912457225

Rotenberg, K., Eisenberg, N., Cumming, C., Smith, A., Singh, M., \& Terlicher, E. (2003). The contribution of adults' nonverbal cues and children's shyness to the development of rapport between adults and preschool children. International Journal of Behavioral Development, 27, 21-30.

http://dx.doi.org/10.1080/01650250143000571

Saunders, P. L., \& Chester, A. (2008). Shyness and the Internet: Social problem or panacea? Computers in Human Behavior, 24, 2649-2658. http://dx.doi.org/10.1016/j.chb.2008.03.005

Scott, C. R. (1999). The impact of physical and discursive anonymity on group members' multiple identifications during computer-supported decision making. Western Journal of Communication, 63, 456487. http://dx.doi.org/10.1080/10570319909374654 
Seidman, G. (2014). Expressing the "true self" on Facebook. Computers in Human Behavior, 31, 367372. http://dx.doi.org/10.1016/j.chb.2013.10.052

Senju, A., \& Johnson, M. H. (2009). The eye contact effect: mechanisms and development. Trends in Cognitive Sciences, 13, 127-134. http://dx.doi.org/10.1016/j.tics.2008.11.009

Shechtman, Z., Hiradin, A., \& Zina, S. (2003). The impact of culture on group behavior: A comparison of three ethnic groups. Journal of Counseling \& Development, 81, 208-216.

http://dx.doi.org/10.1002/j.1556-6678.2003.tb00244.x

Sheldon, P. (2009). "I'll poke you. You'll poke me!" Self-disclosure, social attraction, predictability and trust as important predictors of Facebook relationships. Cyberpsychology: Journal of Psychosocial Research on Cyberspace, 3(2), article 1. Retrieved from:

http://www.cyberpsychology.eu/view.php?cisloclanku=2009111101

Shim, M., Cappella, J. N., \& Han, J. Y. (2011). How does insightful and emotional disclosure bring potential health benefits? study based on online support groups for women with breast cancer. Journal of Communication, 61, 432-454. http://dx.doi.org/10.1111/j.1460-2466.2011.01555.x

Siegman, A. W., \& Reynolds, M. A. (1983). Speaking without seeing, or the effect of interviewer absence on interviewee disclosure time. Journal of Psycholinguistic Research, 12, 595-602.

Sillence, E., \& Briggs, P. (2007). Please advise: Using the Internet for health and financial advice. Computers in Human Behavior, 23, 727-748. http://dx.doi.org/10.1016/j.chb.2004.11.006

Stevens, M. J., Rice, M. B., \& Johnson, J. J. (1986). Effect of eye gaze on self-disclosure. Perceptual and Motor Skills, 62, 939-942.

Stoudt, B. G., \& Ouellette, S. C. (2004). Making room for words: People who stutter on the Internet. Qualitative Research in Psychology, 1, 175-194. http://dx.doi.org/10.1191/1478088704qp013oa

Suler, J. (2004). The online disinhibition effect. CyberPsychology \& Behavior, 7, 321-326.

http://dx.doi.org/10.1089/1094931041291295

Suler, J. (2005). The online disinhibition effect. International Journal of Applied Psychoanalytic Studies, 2, 184-188. http://dx.doi.org/10.1002/aps.42

Suler, J. (2008). Cybertherapeutic theory and techniques. In A. Barak (Ed.), Psychological aspects of cyberspace: Theory, research, applications (pp. 102-128). Cambridge, UK: Cambridge University Press.

Tang, L. (2010). Development of online friendship in different social spaces. Information, Communication \& Society, 13, 615-633. http://dx.doi.org/10.1080/13691180902998639

Tanis, M., \& Postmes, T. (2007). Two faces of anonymity: Paradoxical effects of cues to identity in CMC. Computers in Human Behavior, 23, 955-970. http://dx.doi.org/10.1016/j.chb.2005.08.004

Tourangeau, R., Couper, M. P., \& Steiger, D. M. (2003). Humanizing self-administered surveys: Experiments on social presence in web and IVR surveys. Computers in Human Behavior, 19, 1-24. http://dx.doi.org/10.1016/S0747-5632(02)00032-8

Turkle, S. (2011). Alone together: Why we expect more from technology and less from each other. New York, NY, US: Basic books.

Vondracek, S. I., \& Vondracek, F. W. (1971). The manipulation and measurement of self-disclosure in preadolescents. Merrill-Palmer Quarterly, 17, 51-58.

Walther, J. B. (2007). Selective self-presentation in computer-mediated communication: Hyperpersonal dimensions of technology, language, and cognition. Computers in Human Behavior, 23, 2538-2557

Waring, E. M. (1990). Self-disclosure of personal constructs. Family Process, 29, 399-413.

http://dx.doi.org/10.1111/j.1545-5300.1990.00399.x 
Whitty, M. T., \& Joinson, A. N. (2009). Truth, lies and trust on the Internet. New York, NY: Routledge.

Whitty, M. T., \& McLaughlin, D. (2007). Online recreation: The relationship between loneliness, Internet self-efficacy and the use of the Internet for entertainment purposes. Computers in Human Behavior, 23,1435-1446.

Wodzicki, K., Schwämmlein, E., Cress, U., \& Kimmerle, J. (2011). Does the type of anonymity matter? The impact of visualization on information sharing in online groups. Cyberpsychology, Behavior, and Social Networking, 14, 157-160.

Wright, M. F., \& Li, Y. (2011). The associations between young adults' face-to-face prosocial behaviors and their online prosocial behaviors. Computers in Human Behavior, 27, 1959-1962. http://dx.doi.org/ $10.1016 /$ j.chb.2011.04.019

Yang, M. L., Yang, C. C., \& Chiou, W. B. (2010). Differences in engaging in sexual disclosure between real life and cyberspace among adolescents: social penetration model revisited. Current Psychology, 29, 144154. http://dx.doi.org/10.1007/s12144-010-9078-6

\section{Correspondence to:}

Noam Lapidot-Lefler

Department of Behavioral Science

The Max Stern Yezreel Valley College

Emek Yezreel

19300

Israel

\&

Department of Special Education

The Faculty of Education

Oranim Academic College of Education

Tivon

36006

Israel

Email: noaml(at)yvc.ac.il 


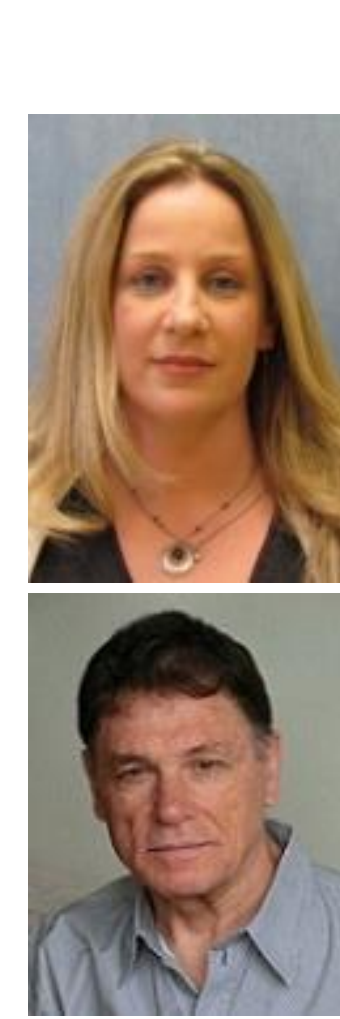

\begin{abstract}
About authors
Noam Lapidot-Lefler, PhD, is a lecturer at the Department of Behavioral Sciences and Education, The Max Stern Yezreel Valley College, and at the Department of Special Education, The Faculty of Education, Oranim College for Education, Israel. Her main research topic centers on Internet psychology, especially on aggression and disinhibition, and, in the field of education, she focuses on special education social spaces.
\end{abstract}

Azy Barak is a professor of psychology in the Department of Counseling and Human Development at the University of Haifa. He is Fellow of the International Society for Mental Health Online (ISMHO), and is an active member of, and received a Lifetime Achievement Award from the International Society for Research on Internet Interventions (ISRII). His research interests include psychological impact of the Internet on individuals, groups, couples, families, and communities, as well as exploitation of the Internet to promote various psychological-related applications. More information can be viewed at http://construct.haifa.ac.il/ azy/azy.htm 